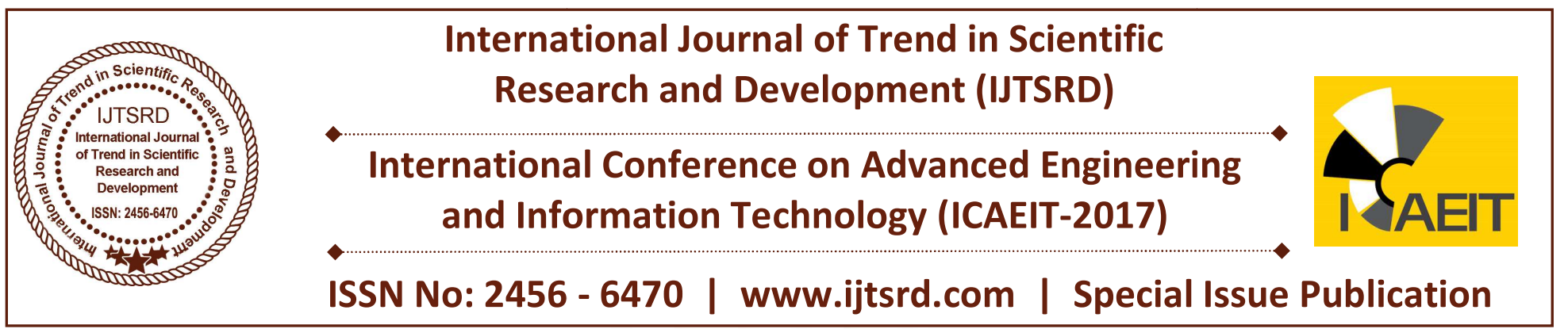

\title{
Process Model of E-Assessment for Accessible and Remote Examination
}

\author{
Feyikunmi Duba Oshodi \\ Leeds Beckett University in Collaboration With \\ Linton University College, Malaysia \\ Mia Torres-Dela Cruz \\ Faculty of Engineering and Technology, \\ Linton University College, Malaysia
}

\author{
Murugananthan Velayutham \\ School of Electrical, Electronic, \\ Mechanical Engineering and Information Technology, \\ Mantin, Malaysia
}

\author{
Mohtar \\ Faculty of Engineering and Technology, \\ Linton University College, Malaysia
}

\begin{abstract}
Online assessments, which includes online examinations, are also called e-examinations, are assessments administered through the internet or in an intranet, if within the organization, in the case of remote examinees for special accessibility cases such as assessment for students with disabilities and with specific learning differences. The system is developed during this project with emphasis on the process model because of specific constraints and risks involved in assessments, and specifically for online examinations.
\end{abstract}

System was developed based on the process models upon requirements analysis. Several tests were carried out on the system to ensure that the functional requirements laid out for the system were met.

Keywords: E-assessment, E-examination, remote examinations, process model

\section{INTRODUCTION}

In education, the learning objectives are established and identified through assessments. This makes it a very essential component in teaching and learning. Decisions about other components of education such as curriculum, syllabi, and instructional requirements are determined. More importantly, decisions about grades, student placement and advancement, and sometimes funding, are largely influenced by assessments.

Assessments would permit educators to assess whether they are teaching what they are supposed to be teaching; if students are learning what they are supposed to; or whether there are better ways to teach the subject to stimulate better learning. Assessment is a core element in the educational system to obtain information about the extent the learning outcome has reached [1].

Technology has made way for education to upgrade also through e-learning and e-assessment. Alsadoon [1] claims that there is an increasing interest in elearning and e-assessment, with more institutions providing it and more students taking it.

One of the most popular assessments in education ever since is the written examinations. Written examinations can be very challenging for both the examiners and the examinees alike since all tasks are manually done such as, student registration, generating examination questions and answers, printing and arranging questionnaires, taking of the exam, marking the answers, and distribution of results. But with the proliferation of computers, it has become easier to do conduct examinations although these are all superficial, like, wordprocessing, 
printing, computing of results and grades, etc. So to take advantage of technology, the development of eassessments would be keeping pace with the times.

One of the e-assessment components is the digitization of examinations, termed as e-examination. From Wordnik's definition [2], e-examination or Computer Based Testing (CBT) is an electronic exam that can be executed by using a personal computer or an equivalent electronic device (e.g. handheld computer).

The project is to develop a system that automates and simplify the process of manual examination. It is considered an e-examination system or an electronic examination system. The system's aims were to effectively automate the examinations process; develop stress-free processes of conducting and taking examinations; and allow remote and accessible examination processes.

The project designed a user-interactive interface and a well-structured database system. It was developed and implemented adequate validation and error/exception handling techniques, and combined the interface and codes to implement a fully functional online examination portal.

The following were the considerations for the system to be completed:

$>$ Security of examination questions and answers: The traditional system is printed in sets. There is a danger of leakage of the paper during encoding or printing or even while passing it to different departments or examination rooms.

Result Processing: Every assessment needs to be marked and the results to be processed. There should be a system that would facilitate verification of answers, timesaving result processing and error-free reports.

Examination Cost: The traditional system is more expensive in the long run considering the materials, printing and labor costs required to prepare and conduct written examination.

> Preparation of Examination Questions and Solutions: The process in preparing examination questions and solutions is quite time consuming and stressful. Traditional system sometimes requires more than one set to be prepared because of the risk of leakages. Then there is the evaluation of peers and other authorized personnel who need to review and approve of the questions and sign verification forms.

Accessibility: Physically-challenged students have limited access to such traditional methods of educations and examination. Design of examinations must consider people with disabilities (permanent or temporary). This concept ensures both "direct access" (i.e. unassisted) and "indirect access" meaning compatibility with a person's assistive technology (for example, computer screen readers) [3]. Currently, the exams are being conducted in specific exam halls, which are difficult to access for students with limb disabilities or physical mobility limitations. There are also students with learning issues that are related to written examinations, i.e. exam phobia, such that online exams are the only way they are able to perform effectively [6].

Research has shown that students benefit a lot from eassessments, specifically, online examination. Many students have exam anxiety and Sambell, Sambell and Sexton [4] reported that they get lesser cases of anxiety when computers were used in their assessments throughout the semester, as students were able to build up their confidence up through this. Students actually expressed their opinions on online tests, they reported that it has helped them to know what to study and has helped in their revision for the exams.

Ayo et al [5] developed a model for e-examination in Nigeria where all applicants are subjected to online entrance examination as a way of curbing examination irregularities that were getting out of hand. The system was proposed by the Joint Admissions Matriculation Board (JAMB) that is saddled with the responsibility of conducting entrance examinations into all the Nigerian universities. The authors claimed that if e-examination is introduced into other institutions in Nigeria it can control and check examination malpractices and all fraudulent acts associated with the manual process of writing examination.

Traditional examinations require the lecturers to each prepare his/her examination questions and then send the respective questions to examiners (both internal 
and external) for review, then the lecturers have to wait for the respective feedbacks. In case that the questions fail the review, the whole process has to be repeated all over and this can be very strenuous on the part of the lecturer. When the questions passed the review, the lecturer then has to print out all pages of the questions for all participating students, this can also be strenuous for the lecturer and also utilizes a lot of resources like ink for the printer, paper to print on, binds to keep all the pages together, if there are more than one, electricity to operate the printer etc. all these processes are tedious enough without any complications, now in a case where the lecturer makes mistakes, or wants to amend something, we can all agree that lots of resources will be wasted. Also, there is the risk of confidentiality, whilst moving the questions from one place to another, there may be a breach and/or leakage of the question which has undermined the standard of the assessment. Even if all these processes are completed without any complications, there is still the challenge of actually conducting the examination, there may be some exceptional cases or reasons for the student(s) not to be present for the exam, which will lead to having to re-take the exam which may lead to a delay in the publication of the results, or to simplify the process in other cases - Failure of the module/subject. While those who are available, after taking the exam, the lecturer has to manually get back all the answer sheets, collate them, assess each of them grade each one and record the scores. Which may take a lengthy period of time depending on the quantity of students and Exam questions, and all these processes must be done carefully, as there is risk of misplacing of answer scripts, or mixing students answers, or even error due to fatigue or omission.

\section{PROPOSED SYSTEM CONCEPT}

The internet has revolutionized almost everything nowadays. Lecturers now utilize computers in teaching, and they can even give out assessments to students without them having to be physically present in the classroom. As a result of this, more and more people are beginning to embrace e-examination system as their preferred examination system.

\section{E-examination Process Model:}

The system does not allow for self-registration, the system will be fully integrated into the existing student management systems, thus the lecturer can register students who are enrolled in his module, and the students will get the username and password sent to their mails thus eliminating the need for docket collection. Also, all the questions in the system will be randomized. This means no two students will get the same question at the same time, this will help to reduce cheating. The whole examination will be timed, from the time the student logs in, the timer will run down, this will assist in effective time management. Also, each question can be timed if the situation requires that. Once the lecturer uploads the question in the question bank, he can set a date and time that the questions will be made available to the students, also the lecturer and the admins can disable and enable the examination questions. If the question is disabled, even if the student logs in with a valid username and password and subject code, there won't be any questions displayed on the screen. The lecturer can also assign marks to each question if he wants to use the auto-grading module. This means that the system will mark the answers, compute the grade and generate suitable reports based on the assessment. The lecturer can also set the display and publishing of results to either immediately the user submits the answers, or at a later date. Also, the system will be capable of automatic answer submission. It means in the case that a student did not finish answering the examination questions, and does not have the chance of submitting his answers before the timer runs out, the questions he has answered will be automatically saved and submitted. The system will also have a back-up feature, which will allow the admin to back up examination details such as questions, answers and the results.

And in this project, MSSQL database is used. In this Project, IIS server will be used as the server for the project. IIS (Internet Information Server) is a group of Internet server made up of a File Transfer Protocol (FTP) and a Hypertext Transfer Protocol (HTTP) specially designed for windows machines or systems. IIS can be viewed as Microsoft's competitor with servers like Apache, O'Reilly and others.

IIS offers many functionalities like it's WYSIWYG user interface that allows for easy building of front end user interfaces, and Microsoft's Active Server Page (ASP) easy integration with ActiveX controls to easily manipulate the content displayed to the users.

An alternative web server that could have been used is the Apache HTTP Web Server. This is an open source Web server application managed by the Apache Software Foundation. Although, there are provisions 
in place for Apache to run on all major operating systems, it is mostly used in combination with Linux distributions.

ISS Web Server is being used in this project mainly because of its easy integration with other Microsoft products and also because it is developed, supported, and maintained by Microsoft Corporation. Provides access to .NET framework \& ASPX scripts, easily integrates with other Microsoft services (Active Directory, MS SQL server, ASP, etc.) Media pack modules are available to enable media content delivery and streaming. And, most importantly it's indepth diagnostic tools such as failed request tracing, request monitoring and runtime data.

The methodology selected has a huge impact on the testing carried out on the developed system. It determines factors like when, what and where of the planned testing, and also to a great extent affects the testing techniques used.

\section{Evaluation and Risk Analysis:}

After testing the build, at the end of first iteration, the user evaluates the software and provides feedback.

This phase includes series of processes which are undertaken to identify risk in the system development and alternate solutions are supplied to address these risks. At the end of this phase a prototype may be developed that which functions as an alternate solution. And these solutions are suggested and implemented if an unwanted risk are discovered during the risk analysis phase. In the evaluation stage of this project, an extensive contingency planning and risk analysis was conducted, also a detailed research into existing system in the college was conducted, other similar systems were reviewed, and compared with the proposed system, also a review of relevant and required technologies to complete the project was conducted.

\section{Engineering Phase:}

This is the phase where the system is actually developed in every iteration process. This phase also includes testing of the developed system. In the subsequent iteration processes there is higher clarity on requirements and design details, then, a working model of the system developed, these models are called Builds and hey have different version number of system product. These builds are sent to customer for feedback.
Evaluation phase:

This phase starts with developing the several conceptual designs in the baseline spiral their designs may be architectural, logical design of modules and units. The main scope of this phase is to allow the customer to evaluate the output of the developed system before the project continues to the next spiral.

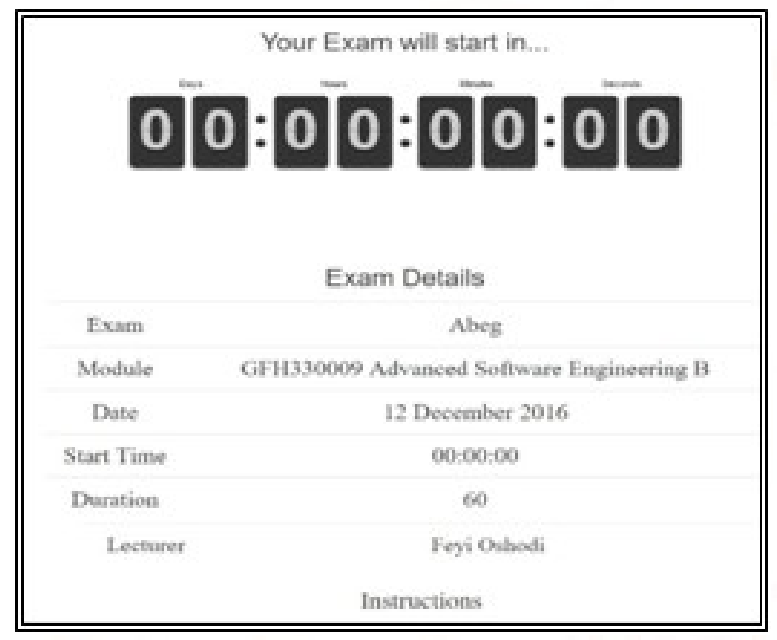

Figure 1: Screenshot of sample exam interface

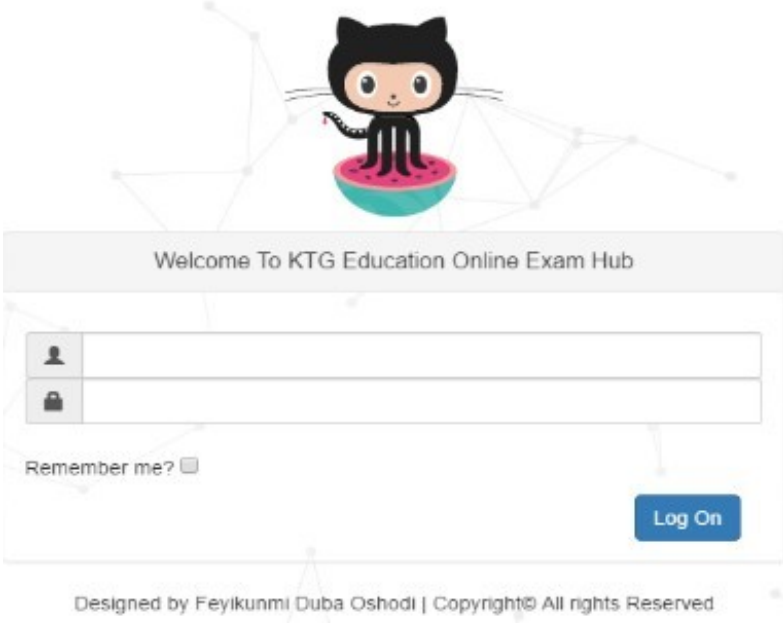

Figure 2: Screenshot of sample exam interface

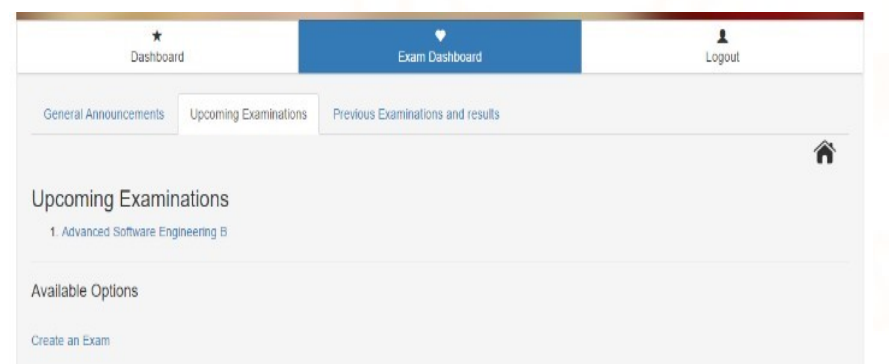

Figure 3: Screenshot of sample exam interface 


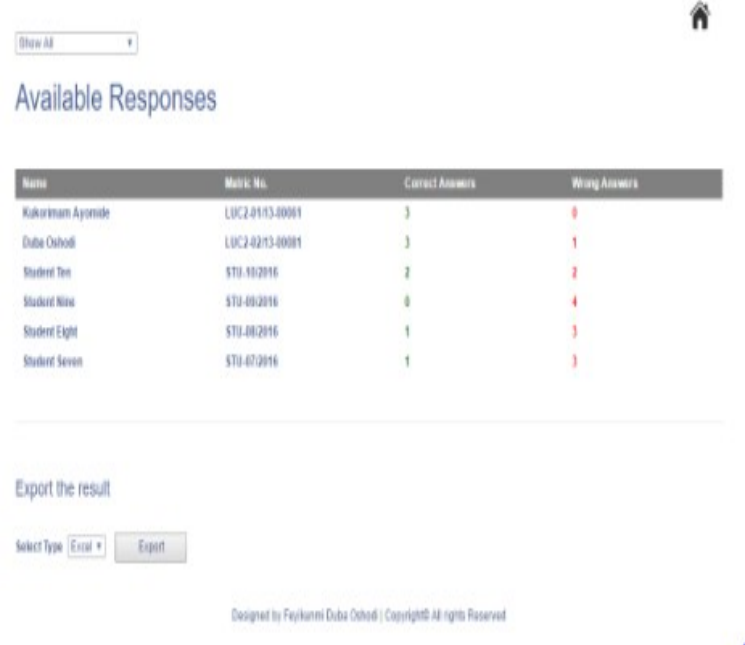

Figure 4: Screenshot of sample exam interface
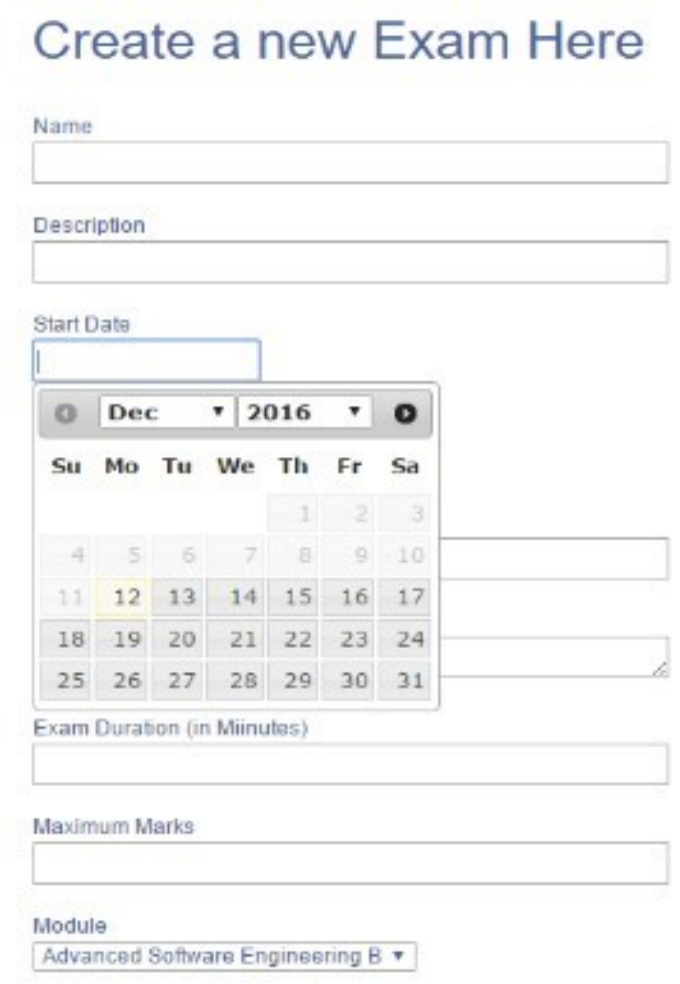

Number of Questions per page

Figure 5: Screenshot of sample exam interface

Congratulations Duba Oshodi below is your Exam report.

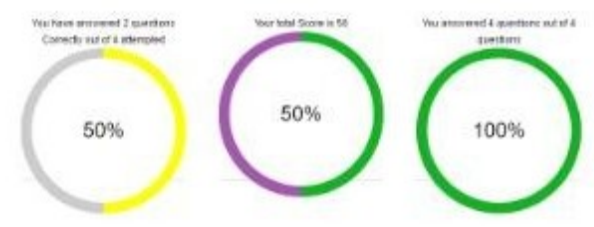

Figure 6: Screenshot of sample exam interface

\section{System Features:}

\section{Administration Features:}

1.1. Able to register/enroll students for an exam

1.2. Able add, update and delete subjects

1.3. Able to create new teachers

1.4. Able to manage question bank

1.5. Able to manage exam results

1.6. Able to set marks for each question (in case of auto marking)

1.7. Able to set timer for each students (In case of special students / disabled)

1.8. Able to enable and disable question papers for accessibility.

\section{Lecturer Features:}

2.1. Able to upload and manage their questions

2.2. Able to register/enroll students for an exam

2.3. Able to Access the students answers for grading

2.4. Able to grade each student

2.5. Able to publish and manage student results

2.6. Able to set marks for each question (in case of auto marking)

2.7. Able to set timer for each students (In case of special students / disabled)

2.8. Able to upload and manage Answers to the questions

\section{System Features:}

3.1. Should randomly generate questions.

3.2. Should allocate time for each exam (as stipulated by the teacher or Admin)

3.3. Should automatically submit students answers when the timer runs out

3.4. Should end the exam when the timer runs out

3.5. Should ensure only registered students are able to take the exam.

3.6. Should ensure students cannot see/take an exam before and after the exam date

3.7. Should ensure students can only see exams enabled by the Admin

3.8. Should be secure

3.9. Should display the questions to the students

3.10. Should allow the student to select/key-in their desired answers

3.11. Should be able to automatically mark and grade the exam (if selected)

3.12. Should be able to store all the questions and answers

3.13. Should allow both students, teachers and admin to login and log out

3.14. Should be able to store the exam results and grades 
3.15. Should be able to display each student's answers to the teacher for grading

3.16. Should be interactive

3.17. Should be user friendly

3.18. Should be able to allow students take either Tests or Examination

3.19. If students are taking tests, results may be displayed to the students immediately

3.20. If students are taking examination, the student's marks and grades can only be enabled by the admin or teacher.

\section{Conclusion}

The e-assessment system was developed using ASP.Net framework and C\# Programming Language as the front end, and MSSQL as the backend database. The system fully meets all the requirements for which it was developed and addresses the problem that lead to the need for the system in the first place. Extensive tests were carried out to detect, identify and eliminate any bugs/defects to deliver a stable and functional system. The intended users were involved actively in the implementation and testing of the system, so it is tailored to be user friendly, and easy-to-use for the end users. Future enhancement of the system can be: An admin interface can be added to the system for effective management; The system can be enhanced so that, the lecturer has to register students for exam based on their attendance in the exam hall. So, even if the exam is available, student cannot take it unless the lecturer registers them; The system can be enhanced to detect page refresh and disable back button; and, The system can be enhanced to detect late attendance, and adjust the timer accordingly.
5. References

1. Alsadoon, H., 2017, Students' Perceptions of EAssessment at Saudi Electronic UniversityTurkish Online Journal of Educational Technology TOJET, v16 n1 p147-153 Jan 2017

2. "Wordnik", Wordnik.com, 2017. [Online]. Available:https://www.wordnik.com/words/eexam. [Accessed:13- Nov- 2017].

3. "Accessibility Information for Persons with Disability", Disabled World, 2017. [Online]. Available: https:/www.disabledworld.com/disability/accessibility/. [Accessed: 04Nov-2017].

4. Sambell, K., Sambell, A. \& Sexton, G. (1999) Using computer-aided assessment In McDowell, L. (Ed) Using Information Technology in Teaching, Learning \& Assessment Marcet, UNN: Red Guide.

5. C. K. Ayo, I.O. Akinyemi, A.A. Adebiyi, U.O. Ekong, (2007) The Prospects of E-Examinaiton Implementation in Nigeria. Turkish Online Journal of Distance Education-TOJDE October 2007 ISSN 1302-6488 Volume: 8 Number: 4 Article 10

6. "Written exams to be replaced by online tests in effort to help 'exam-phobic' pupils", Mail Online, 2017. [Online]. Available: http://www.dailymail.co.uk/news/article1199300/Written-exams-replaced-online-testseffort- help-exam-phobic-pupils.html. [Accessed: 30- Oct-2017]. 